Tropical Journal of Pharmaceutical Research January 2019; 18 (1): 117-121

ISSN: $1596-5996$ (print); 1596-9827 (electronic) (c) Pharmacotherapy Group, Faculty of Pharmacy, University of Benin, Benin City, 300001 Nigeria.

\title{
Assessment of knowledge and attitude of patients on herbal medicine use in Udupi region, Karnataka, India
}

\author{
Bhavana B Bhat ${ }^{1}$, N Udupa ${ }^{2}$, Virendra S Ligade', Saleemulla Khan ${ }^{3}$, D \\ Sreedhar ${ }^{1 *}$ \\ ${ }^{1}$ Department of Pharmacy Management, Manipal College of Pharmaceutical Sciences, ${ }^{2}$ Directorate of Research (Health \\ Sciences), Manipal Academy of Higher Education, Manipal-576104, ${ }^{3}$ P.A. College of Pharmacy, Nadupadav Post, Kairangala, \\ Managalore, Karnataka, India
}

*For correspondence: Email: d.sreedhar@manipal.edu; Tel: +91-8202922482

Sent for review: 17 August 2018

Revised accepted: 13 December 2018

\begin{abstract}
Purpose: To determine the knowledge and attitude of patients on the usage of herbal medicines in Udupi Region of Karnataka State, India.

Methods: This was a descriptive, cross-sectional study, carried out over a period of six months, and involving a structured and validated questionnaire. It was conducted among patients who visited hospitals in and around the Udupi region of Karnataka, India.

Results: About $37 \%$ of the respondents of the study used a combination of allopathy and herbal medicines. The results further showed that $29.8 \%$ of respondents used allopathy, while $24.5 \%$ were on herbal medicines. Of the total herbal medicine users, $34.07 \%$ of the respondents stated that the reason for using herbal medicines was their perception that herbal medicines had more efficacy and comparatively lower side effects. A majority of the respondents, i.e., $64.6 \%$, lacked knowledge on dose, duration of therapy, side effects and interactions of the drugs. Out of 226 respondents who used herbal medicine, only $65(28.76 \%)$ could identify adverse drug reactions (ADRs). Among these 65 patients who could identify ADRs, only $16(24.62 \%)$ informed the physician about it, while the remaining 49 (75.38\%) patients did not inform the physician about it.

Conclusion: The results indicate a need to conduct educational and awareness programs by AYUSH, The Ministry of Ayurveda, Yoga and Naturopathy, Unani, Siddha and Homoeopathy on herbal medicines and adverse drug reactions in order to minimize untoward effects caused by herbal medicines.
\end{abstract}

Keywords: Ayurveda, Knowledge, Attitude, Patient, Adverse drug reactions (ADRs), Herbal medicines

This is an Open Access article that uses a funding model which does not charge readers or their institutions for access and distributed under the terms of the Creative Commons Attribution License (http://creativecommons.org/licenses/by/4.0) and the Budapest Open Access Initiative (http://www.budapestopenaccessinitiative.org/read), which permit unrestricted use, distribution, and reproduction in any medium, provided the original work is properly credited.

Tropical Journal of Pharmaceutical Research is indexed by Science Citation Index (SciSearch), Scopus, International Pharmaceutical Abstract, Chemical Abstracts, Embase, Index Copernicus, EBSCO, African Index Medicus, JournalSeek, Journal Citation Reports/Science Edition, Directory of Open Access Journals (DOAJ), African Journal Online, Bioline International, Open-J-Gate and Pharmacy Abstracts

\section{INTRODUCTION}

Man has been using herbal medicines since the inception of his life on earth. Herbal medicines have been often used as first aid even before a patient has access to the healthcare facilities [1].
The use of herbal medicines has been increasing worldwide. More than $80 \%$ of the population across the globe use herbal medicines for primary healthcare [2]. Many who once drifted away from herbal medicines towards modern medicine are now resuming their way back to this 
system of medicine, mainly due to their different assumptions and beliefs [3]. Most of the patients are dissatisfied with modern medicine because of the adverse drug reactions associated with these medicines $[4,5]$.

There are different forms of herbal medicines used in India. Ayurveda is commonly practiced and used among Indian population for various disorders. According to some study, Ayurveda originated from India and is being practiced here for more than 5000 years [6]. This medical system predominantly uses herbs and minerals as curative and preventive agents [7]. Though 70 $\%$ of the population in India primarily use herbal medicines, there is a lack of research on these medicines $[8,9]$.

The attitude and behaviour of the patients towards herbal medicines is of a great concern for regulators and policy makers. With increased curiosity and orientation towards herbal medicines, there is a proportionate increase in the production, sale and advertisement of these medicines. However, there is considerable knowledge deficit in this area of herbal medicines. Yet, some patients have a strong belief in most natural medicines, and consider them safe [10].

A study conducted by Vickers et al in a group of women who used herbal medicine showed a poor doctor-patient relationship, poor knowledge on the herb drug interactions [11]. In another study conducted among 493 diabetes patients, high prevalence $(67.7 \%)$ of complementary and alternative medicines (CAM) use was observed. Although the patients were aware of CAM therapy, there was dissatisfaction with the treatment, which further suggested the need for education on CAM [12]. However, studies of this sort were not found in India, where herbal medicines are used in plenty. Therefore, it was thought appropriate to conduct an elaborative study among the local population. Thus, the objective of the study was postulated. This study was conducted to determine the knowledge and attitude about herbal medicines among patients of Udupi region.

\section{METHODS}

\section{Study design and sample size}

The study was a descriptive cross-sectional survey. Convenience sampling method was used to collect the responses from patients visiting hospitals in and around Udupi region of Karnataka, one of the states in India. The sample size was not calculated, and it does not represent the total population. However, the responses were collected in a fixed duration of time of three months. The patients who were aged above 15 years and literate were eligible for this study. Data were collected from hospital premises and public places. Only those patients, irrespective of their disease or condition, who were interested in the study were included, and hence the response rate was $100 \%$. A total of 322 patients participated in the study.

\section{Ethical approval}

The study was approved by Kasturba Hospital Institutional Ethics Committee (approval no. IEC 244/2014). Kasturba Hospital Institutional Ethics Committee is accredited by AAHRPP (Association for the Accreditation of Human Research protection Program). The study was conducted in accordance with ICH-GCP guidelines [13]. The patients were asked to sign an informed consent form and the investigator explained to them about the study. Informed consent included following aspects:

The patients need to respond to a few questions, will be educated about the disease diet and medication, will be asked to report any side effects to the investigator and will be educated about the importance of adherence to therapy. The participants of the study were informed that the outcomes of the study will be published.

There is no record of the patient's name in the questionnaire, and hence the patient confidentiality was maintained.

\section{Development of questionnaire}

The questionnaire was prepared in two different languages, English and Kannada. The questionnaire contained eight questions and were categorized into knowledge and attitude based questions. Of the total eight questions, four were knowledge based (Questions 1, 2, 4 and 8 ) and rest were attitude based (Questions 3, 5, 6 and 7). Knowledge based questions were given one mark each and attitude based questions were given two marks for a "yes" response, one mark for neutral and zero for a "no" response.

A structured questionnaire was prepared and given to subject experts for their comments. According to the subject experts' comments or suggestions changes in the questions were made. Questions were closed ended, containing either dichotomous or multiple choice questions. For checking repeatability, responses were collected from a total of 21 patients on day 1 , and 
again the responses were collected from the same set of patients on day 15 by contacting them over phone. Cronbach alpha score was found to be 0.98 and intra-class coefficient was found to be 0.983 when the questionnaire was tested for uniformity in the responses.

\section{Questionnaire distribution, collection and analysis of data}

Questionnaires were distributed among patients in the study area, i.e., hospital premises and public places. The investigator briefed them about the study and informed consent was taken before administering the questionnaire to the patients. The questionnaire was distributed to each patient at a time, and the responses were collected. Based on the responses obtained from the questionnaires, results were tabulated and analyzed.

The patient population were from both rural as well as urban areas of Udupi. Patients' demographic data like age and sex was collected through the questionnaire. However, comparison of responses was only made on the basis gender.

The comparison of data was done using nonparametric tests like Mann-Whitney U Test. The data was compiled and analyzed statistically using SPSS 18 software.

\section{RESULTS}

\section{Demographic profile}

Out of 322 participants, $45.7 \%$ were female and $54.3 \%$ were male. The mean age of the respondents was $43.02 \pm 14.33$ years, and median age was found to be $41.0 \pm 14.33$ years. Nearly half $(46.3 \%)$ of the total respondents were aged between $25-44$ years and $38.8 \%$ were aged between 45 - 64 years (Table 1).

\section{Classification of different types of medicines used by respondents}

namely, Ayurveda, Allopathy, Homeopathy and Combination. Out of 322 respondents, $70.2 \%$ were using some form of herbal medicines, either alone (Ayurveda: $24.5 \%$, Homeopathy: $8.7 \%$ ) or in a combination (37\%), and around $28.8 \%$ were using allopathy medicines (Table 2). Majority of the respondents who used different types of medicines were in the age groups 2 (25 -44 years) and 3 ( $45-65$ years) (Table 3 ).

\section{Reasons for use of herbal medicines}

Of the total 322 respondents, 226 (70.1\%) were using herbal medicines and combination medicines. Majority (34.07\%) have said that they used herbal medicines because they are more efficacious, have fewer side effects and are safer than conventional drugs (Table 4).

Table 1: Age of the patients

\begin{tabular}{lcc}
\hline $\begin{array}{l}\text { Demographic } \\
\text { characteristic }\end{array}$ & \multicolumn{2}{c}{ Patient } \\
\hline \multicolumn{1}{c}{$\boldsymbol{N}$} & $\%$ \\
\hline Gender & & \\
Male & 175 & 54.3 \\
Female & 147 & 45.7 \\
Age (yr) & & \\
Group 1 (15-24) & 27 & 8.4 \\
Male & 13 & 48.15 \\
Female & 14 & 51.85 \\
Group 2 (25-44) & 149 & 46.3 \\
Male & 83 & 55.70 \\
Female & 66 & 44.30 \\
Group 3 (45-64) & 125 & 38.8 \\
Male & 64 & 51.2 \\
Female & 61 & 48.8 \\
Group 4 (65 and above) & 21 & 6.5 \\
Male & 15 & 71.43 \\
Female & 6 & 28.57 \\
$\quad$
\end{tabular}

Table 2: Medication category

\begin{tabular}{lcc}
\hline Category & Frequency & $\begin{array}{c}\text { Percent } \\
\text { age }\end{array}$ \\
\hline Ayurveda & 79 & 24.5 \\
Homeopathy & 28 & 8.7 \\
Allopathy & 96 & 29.8 \\
Combinations & 119 & 37.0 \\
Total & 322 & 100.0 \\
\hline
\end{tabular}

The respondents were classified into four categories based on the usage of medicines,

Table 3: Medication type according to age group

\begin{tabular}{lllllllll}
\hline \multirow{2}{*}{$\begin{array}{c}\text { Age group } \\
\text { (in years) }\end{array}$} & \multicolumn{2}{l}{ Ayurveda } & \multicolumn{2}{c}{ Homeopathy } & \multicolumn{2}{c}{ Allopathy } & \multicolumn{2}{c}{ Combination } \\
\cline { 2 - 9 } & $\boldsymbol{N}$ & $\%$ & $\boldsymbol{N}$ & $\%$ & $\boldsymbol{N}$ & $\%$ & $\boldsymbol{N}$ & $\%$ \\
\hline $15-24$ & 4 & 5.06 & 03 & 10.71 & 9 & 9.38 & 11 & 9.24 \\
$25-44$ & 37 & 46.84 & 14 & 50.00 & 37 & 38.54 & 61 & 51.26 \\
$45-64$ & 32 & 40.51 & 10 & 35.71 & 44 & 45.83 & 39 & 32.77 \\
65 and above & 6 & 7.59 & 1 & 3.58 & 6 & 06.25 & 8 & 6.73 \\
Total & 79 & 100 & 28 & 100 & 96 & 100 & 119 & 100 \\
\hline
\end{tabular}


Table 4: Reasons for use of herbal medicines

\begin{tabular}{lll}
\hline Reason & No & $\%$ \\
\hline Simple and easily available & 19 & 8 \\
Cheaper & 25 & 11 \\
More efficacy and lesser side & 77 & 34 \\
effects & & \\
Safer than conventional drugs & 60 & 27 \\
$\begin{array}{l}\text { Preventing complications } \\
\text { Total }\end{array}$ & 45 & 20 \\
\hline
\end{tabular}

Table 5: Action taken after identification of ADRs

\begin{tabular}{lll}
\hline Response & No & $\%$ \\
\hline Reported to physician & 16 & 24.61 \\
Continued medication & 8 & 12.31 \\
Reduced dosage without & 9 & 13.85 \\
consultation & & \\
Chose an alternative therapy & 18 & 27.69 \\
Stopped the medication & 14 & 21.54 \\
Total & 65 & \\
\hline
\end{tabular}

\section{Patients' knowledge about herbal medicines}

The major sources of information regarding herbal medicines were friends $(32.74 \%)$ and drug advertisements (32.30\%). The maximum score for knowledge was 4 and the mean knowledge score was 2.81 (SD, 0.46). Results were analyzed using Mann-Whitney test, which showed that males had better knowledge about herbal medines (Mean knowledge score: 2.77) than females (Mean knowledge score: 1.81).

\section{Patients' attitude towards herbal medicines}

A maximum of score 8 was allocated for attitude. Mean score was found to be 2.86 (SD,: 0.41 ). Of the 226 respondents, $35.4 \%$ of them had a fair knowledge on dose, duration of therapy, side effects and interactions of the drugs used. However, $64.6 \%$ of the respondents were unaware of the same. If the patients had a fair knowledge of dose, duration of therapy, side effects and interactions of the drugs used, it was considered as a "positive response". If the patients were not aware of the pharmacological effects and interaction of drugs, it was considered as "negative response".

\section{Identification of ADRs}

Out of 226 respondents, $65(28.76 \%)$ of them could identify ADRs, 89 (39.38\%) of them could not identify any ADRs and $72(31.86 \%)$ of them were not sure if they have come across an ADR. Though the number of patients who could identify the ADRs were 65 , only 16 of them reported about this to the physician.

\section{Action taken after identification of ADRs}

Of 226 respondents only $28.76 \%$ of them could identify or felt ADRs. About $24.61 \%$ reported it to their physician, and the rest of them took decision on their own. Of the patients who have taken decision, $27.69 \%$ respondents chose an alternative therapy, $21.54 \%$ stopped the medication, $13.85 \%$ reduced dosage without consultation and $12.31 \%$ continued the medication (Table 5). Mann-Whitney test showed that there was no significant difference in the attitude scores between gender and herbal medicine users $(p<0.483)$.

\section{DISCUSSION}

The results of the study showed that a majority of the study population were using some or the other form of herbal medicines. Wachtel-Galor et al states that about $70 \%$ of the Indian population were dependent on herbal medicines [14]. The percentage of allopathy users are higher when compared to Ayurveda. It was found that herbal medicines were used more by male than females in this study. However, Kristoffersen et al showed that women were more frequent users of herbal medicines [15]. A higher number of respondents were using combination therapies, compared to single medication category.

Furthermore, the respondents felt that herbal medicines were mostly preferred to conventional medicines since they are more efficacious and have minimal side effects. Martins Ekor has put forwarded the factors that affect the increase in usage of herbal medicines [16]. This study shows that the strongest influence for the use of herbal medicines were friends, followed by drug advertisements. This was similar to a study conducted by Hon et al, which showed that the common source of information among traditional Chinese medicine users was family and friends [17]. Further, the results show that there were statistically insignificant differences in both knowledge score as well as attitude score. The findings of this study were similar to the results put forwarded by Chen et al for both knowledge and attitude score for the use of traditional Chinese medicine [18].

\section{Limitations of the study}

In this study, the convenience sampling method was used, and thus the sample size is small when compared to the whole population. The survey was conducted in comparatively a smaller region, i.e., in and around Udupi. Though patients were literate enough, the chances of randomly ticking the options might have 
occurred. Hence, a conclusion cannot be drawn from the present study. A larger group of people, using probability methods for sampling and large area for conducting a similar study may provide conclusive results.

\section{CONCLUSION}

The findings of the study indicate diverse knowledge and attitudes among the patients on the usage of herbal medicines in the study setting. AYUSH, The Ministry of Ayurveda, Yoga and Naturopathy, Unani, Siddha and Homoeopathy need to conduct awareness programs on the use of herbal medicines and their adverse drug reactions in order to minimize untoward effects in patients that use herbal medicines.

\section{DECLARATIONS}

\section{Acknowledgement}

The authors thank Manipal College of Pharmaceutical Sciences, Manipal Academy of Higher Education, Manipal, India for providing the facilities used to carry out this study.

\section{Conflict of interest}

No conflict of interest is associated with this work. No funding was received to conduct the study.

\section{Contribution of authors}

We declare that this work was done by the authors named in this article and all liabilities pertaining to claims relating to the content of this article will be borne by the authors. This is hereby declared that $\mathrm{D}$ Sreedhar has conceived and designed the study, N Udupa validated questionnaire and coordinated with hospital authorities and Bhavana B Bhat collected the data. Bhavana B Bhat, Virendra S Ligade and Saleemullah Khan analyzed the data. Finally, D Sreedhar and Bhavana Bhat wrote the manuscript. All authors read and approved the final manuscript for publication.

\section{REFERENCES}

1. Teferi $D L$, Sundara RM. Demand for traditional health care services in Rural Ethiopia. Middle East J Sci Res 2013, 13: 1-10.13
2. Kamboj VP. Herbal medicines. Curr Sci 2000, 78: 1.

3. Jeny N. Public expenditure on traditional medicine in India. EPRA Int J Econ Bus Rev 2016, 4(3): 146-149.

4. Sanjoy KP, Yogeshwer S. Herbal Medicine: Current Status and the Future. Asian Pacific J Cancer Prev 2003; 4: 281-288.

5. Zhang J, Onakpoya IJ, Posadzki P, Eddouks M. The safety of herbal medicine: From prejudice to evidence. Evid Based Complement Altern Med 2015; Article ID 316706.

6. Ayurvedic Medicine: In Depth. National Center for Complimentary and Integrative Health. Available at: https://nccih.nih.gov/health/ayurveda/introduction.htm

7. Tabish SA. Complementary and alternative healthcare: Is it Evidence-based? Int J Health Sci (Qassim) 2008, 2(1): 5-9.

8. Brater DC, Daly WJ. Clinical pharmacology in the middle Ages: Principles That Presage the 21st Century. Clin Pharmacol Ther 2000, 67: 447-440.

9. Herbal Medicine Today: Clinical and Research Issues. Evid Based Complement Altern Med 2007; 4: 37-40.

10. Barnes J. Herbal Therapeutics: An Introduction to Herbal Medicinal Products. Pharm J 2002; 268: 803.

11. Vickers $K A$, Jolly KB, Greenfield SM. Herbal medicine: women's views, knowledge and interaction with doctors: a qualitative study. BMC Complement Altern Med 2006; 6: 40 .

12. Kumar D. Knowledge, attitude and practice of complementary and alternative medicines for diabetes. Public Health 2006; 120(8): 705-711.

13. Guideline for Good Clinical Practice E6 (R1). [Cited 2018 Nov 28]. Available at: https://www.ich.org/fileadmin/ Public_Web_Site/ICH_Products/Guidelines/Efficacy/E6/ E6_R1_Guideline.pdf

14. Sissi WG. Herbal Medicine: An Introduction to Its History, Usage, Regulation, Current Trends, and Research Needs. 2nd edition. Boca Raton (FL): CRC Press/Taylor \& Francis 2011.

15. Agnete EK. Gender differences in prevalence and associations for use of CAM in a large population study. BMC Complement and Alter Med 2014; 14: 463.

16. Martins E. The growing use of herbal medicines: Issues relating to adverse reactions and challenges in monitoring safety. Front Phramacol 2013; 4: 177

17. KI H, Twinn SF, Leung TF, Thompson DR, Wong Y, Fok TF. Chinese nursing students' attitudes toward traditional Chinese medicine. J Nurs Educ 2004; 12(2): 182-185.

18. Chen B, Bernard A, Cottrell R. Differences between family physicians and patients in their knowledge and attitudes regarding traditional Chinese medicine. Integr Med 1999; 2: 45-55. 